$N 70-33060$

NASA TECHNICAL MEMORANDUM

Nิ
กิ
$x$
$\sum$
$\sum$
$\sum$
$z$

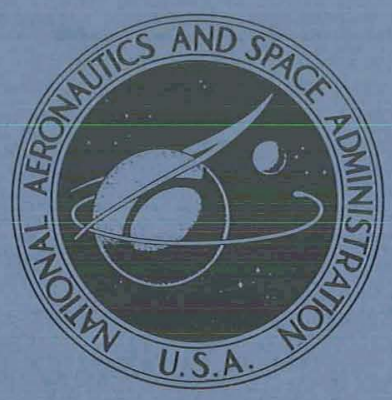

NASA TM X-2052

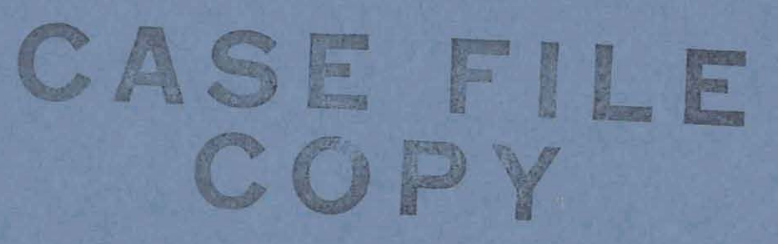

\title{
A NEW APPROACH TO THE SMALL ACCELERATOR VACUUM SYSTEM
}

by Robert Steinberg and Donald L. Alger

Lewis Research Center

Cleveland, Obio 44135

NATIONAL AERONAUTICS AND SPACE ADMINISTRATION - WASHINGTON, D. C. • JULY 1970 


\begin{tabular}{|c|c|c|c|c|}
\hline $\begin{array}{l}\text { 1. Report No. } \\
\text { NASA TM X-2052 }\end{array}$ & \multicolumn{2}{|c|}{ 2. Government Accession No. } & \multicolumn{2}{|c|}{ 3. Recipient's Catalog No. } \\
\hline \multirow{2}{*}{\multicolumn{3}{|c|}{$\begin{array}{l}\text { 4. Title and Subtitle } \\
\text { A NEW APPROACH TO THE SMALL ACCELERATOR } \\
\text { VACUUM SYSTEM }\end{array}$}} & \multicolumn{2}{|l|}{$\begin{array}{l}\text { 5. Report Dare } \\
\text { July } 1970\end{array}$} \\
\hline & & & \multicolumn{2}{|c|}{ 6. Performing Organization Code } \\
\hline \multicolumn{3}{|c|}{$\begin{array}{l}\text { 7. Author(s) } \\
\text { Robert Steinberg and Donald L. Alger }\end{array}$} & \multicolumn{2}{|c|}{$\begin{array}{l}\text { 8. Performing Organization Raport No. } \\
\text { E- } 5653\end{array}$} \\
\hline \multirow{3}{*}{\multicolumn{3}{|c|}{$\begin{array}{l}\text { 9. Performing Organization Name and Address } \\
\text { Lewis Research Center } \\
\text { National Aeronautics and Space Administration } \\
\text { Cleveland, Ohio } 44135\end{array}$}} & \multicolumn{2}{|l|}{$\begin{array}{l}\text { 10. Work Unit No. } \\
129-02\end{array}$} \\
\hline & & & \multicolumn{2}{|c|}{ 11. Contract or Grant No. } \\
\hline & & & \multicolumn{2}{|c|}{ 13. Type of Report and Period Covered } \\
\hline \multirow{2}{*}{\multicolumn{3}{|c|}{$\begin{array}{l}\text { 12. Sponsoring Agency Name and Address } \\
\text { National Aeronautics and Space Administration } \\
\text { Washington, D. C. } 20546\end{array}$}} & \multicolumn{2}{|c|}{ Technical Memorandum } \\
\hline & & & \multicolumn{2}{|c|}{ 14. Sponsoring Ageney Codo } \\
\hline \multicolumn{5}{|l|}{ 15. Supplementary Notes } \\
\hline \multicolumn{5}{|c|}{$\begin{array}{l}\text { 16. Abstroct } \\
\text { The incorporation of a titanium bulk sublimator in combination with a getter ion pump in } \\
\text { a small accelerator vacuum system is shown to provide major advantages in pumping } \\
\text { performance, reduction of the tritium hazard, and improvement in system reliability. } \\
\text { A mode of operation is suggested for the sublimator which can greatly increase subli- } \\
\text { mator lifetime. Typical operating data for the vacuum system of a 300-kilovolt accel- } \\
\text { erator equipped with a sublimator/ion pump combination are presented. A suggestion for } \\
\text { the adaptation of a comparable vacuum system to a standard 150-kilovolt accelerator is } \\
\text { made. }\end{array}$} \\
\hline \multicolumn{2}{|c|}{$\begin{array}{l}\text { 17. Key Words (SugBested by Author(s)) } \\
\text { Pumping hydrogen } \\
\text { Accelerator vacuum systems } \\
\text { Sublimation pumping } \\
\text { Neutron generator }\end{array}$} & \multicolumn{3}{|c|}{$\begin{array}{l}\text { 18. Distribution Statement } \\
\text { Unclassified - unlimited }\end{array}$} \\
\hline $\begin{array}{c}\text { 19. Security Clossif. (of this repori) } \\
\text { Unclassified }\end{array}$ & 20. & $\begin{array}{l}\text { sif. (of this page) } \\
\text { assified }\end{array}$ & $\begin{array}{c}\text { 21. No. of Poges } \\
10\end{array}$ & $\begin{array}{l}\text { 22. Price* } \\
\$ 3.00\end{array}$ \\
\hline
\end{tabular}

*For sale by the Clearinghouse for Federal Scientific and Technical Information Springfield, Virginia 22151 


\title{
A NEW APPROACH TO THE SMALL ACCELERATOR VACUUM SYSTEM \\ by Robert Steinberg and Donald L. Alger \\ Lewis Research Center
}

\begin{abstract}
SUMMARY
The incorporation of a titanium bulk sublimator in combination with a getter ion pump in a small accelerator vacuum system is shown to provide major advantages in pumping performance, reduction of the tritium hazard, and improvement in system reliability. A mode of operation is suggested for the sublimator which can greatly increase sublimator lifetime. Typical operating data for the vacuum system of a 300-kilovolt accelerator equipped with a sublimator/ion pump combination are presented. A suggestion for the adaptation of a comparable vacuum system to a standard 150 -kilovolt accelerator is made.
\end{abstract}

\section{INTRODUCTION}

The work reported here is directed towards the improvement of vacuum systems for positive ion accelerators in the 100- to 500-kilovolt range that are used primarily for the production of neutrons. Many investigators working with small accelerators that utilize oil diffusion pumping only have found such vacuum systems to be marginal. In an attempt to eliminate some of the disadvantages of oil diffusion pumping (i.e., target contamination, tritium release through the roughing pump, liquid nitrogen cost) several accelerator manufacturers have introduced the getter ion pump. Because of tritium saturation of the getter ion pump, frequent replacement is required, and tritium exposure hazards are introduced. The replacement costs and hazards have made the use of the getter ion pump less than satisfactory (ref. 1).

A well designed vacuum system for a small accelerator should meet the following specifications:

(1) Fast pump down from atmosphere to $10^{-7}$ torr

(2) High pumping speeds for increased gas loads 
(3) Long term maintenance free operation

(4) Completely sealed vacuum system to contain tritium released from the target and to prevent vacuum loss due to power failure

In order to achieve these design criteria, the prevailing concept of using a single pump (not including the roughing system) to hold the system under vacuum and to handle the high gas load during operation must be rejected. The foregoing specifications for a vacuum system can be met by utilizing separate pumping methods more suitable for each specific gas load.

It is shown that the incorporation of a titanium bulk sublimator in combination with a getter ion pump offers a significant improvement in vacuum system performance and reliability with an accompanying reduction of the tritium hazard.

\section{SEPARABLE PUMPING FUNCTIONS}

When the gas load consists entirely of surface outgassing and residual leakage, the vacuum can be effectively maintained by a small getter ion pump. During accelerator operation with deuterium, however, a pump designed specifically for a high deuterium gas load should be used to maintain vacuum.

A titanium bulk sublimator (TBS) because of its large pumping capacity for hydrogen and its isotopes meets high deuterium gas load requirements (ref. 2). The TBS is essentially a device containing a rod of titanium which can be heated to $1500^{\circ} \mathrm{F}\left(815^{\circ} \mathrm{C}\right)$ in order to sublime the titanium onto a water cooled surface (substrate). The freshly deposited titanium forms stable solid compounds with chemically active gas molecules that strike the surface and result in high pumping speeds for hydrogen, oxygen, nitrogen, carbon monoxide, carbon dioxide, and water vapor. A TBS cannot, however, pump inert gases or hydrocarbons. By using a TBS in combination with a getter ion pump, which handles the hydrocarbons and the inert gases, major advantages in vacuum system performance and reliability are obtained. The TBS provides a variable pumping speed from several liters per second to over 100000 liters per second $\left(100 \mathrm{~m}^{3} / \mathrm{sec}\right)$ depending on gettering surface area and conductance limitations. A single 400-gram charge of titanium is estimated to be sufficient to provide a TBS operating lifetime of over 10 years for a typical 150-kilovolt accelerator.

When tritium targets are used, the tritium gas released will be permanently buried in the walls of the TBS as titanium tritide. It has been shown (ref. 3) that over 85 percent of the tritium released from targets in commercial accelerators ends up in the getter ion pump, or if an oil diffusion pump is used, tritium gas is released to the atmosphere. The use of a TBS in combination with a getter ion pump minimizes tritium contamination of the ion pump and other parts of the vacuum system. 


\section{VACUUM SYSTEM FOR 300-KILOVOLT ACCELERATOR}

A 300-kilovolt 15-milliampere positive ion accelerator utilizing sublimation pumping has been in operation at Lewis for the past 2 years. The vacuum system for this machine consists of three sorption pumps for roughing down, a 270-liter-per-second $\left(0.27 \mathrm{~m}^{3} / \mathrm{sec}\right)$ getter ion pump for maintaining the system ultimate pressure of $7 \times 10^{-8}$ torr, and a 400-gram TBS pump for handling large deuterium and tritium gas loads. The volume of the accelerator under vacuum is about 300 liters.

In figure 1 are shown typical pumpdown and accelerator operating vacuum conditions with and without the use of the TBS pump. Considerable difficulty was experienced in obtaining an operating vacuum without the use of the sublimator. This is shown by the dotted curve, which indicates that pumping was slow in the $10^{-3}$ torr range with the required vacuum gradually approached in about 5 hours. This mode of operation was modified by the observation that, contrary to the manufacturer's recommendation that the TBS should not be started above $1 \times 10^{-4}$ torr, the sublimator could indeed be started at between 1 and $2 \times 10^{-2}$ torr, thus providing substantial pumping in a difficult pressure range. The sublimator getter-ion pump combination has subsequently been started

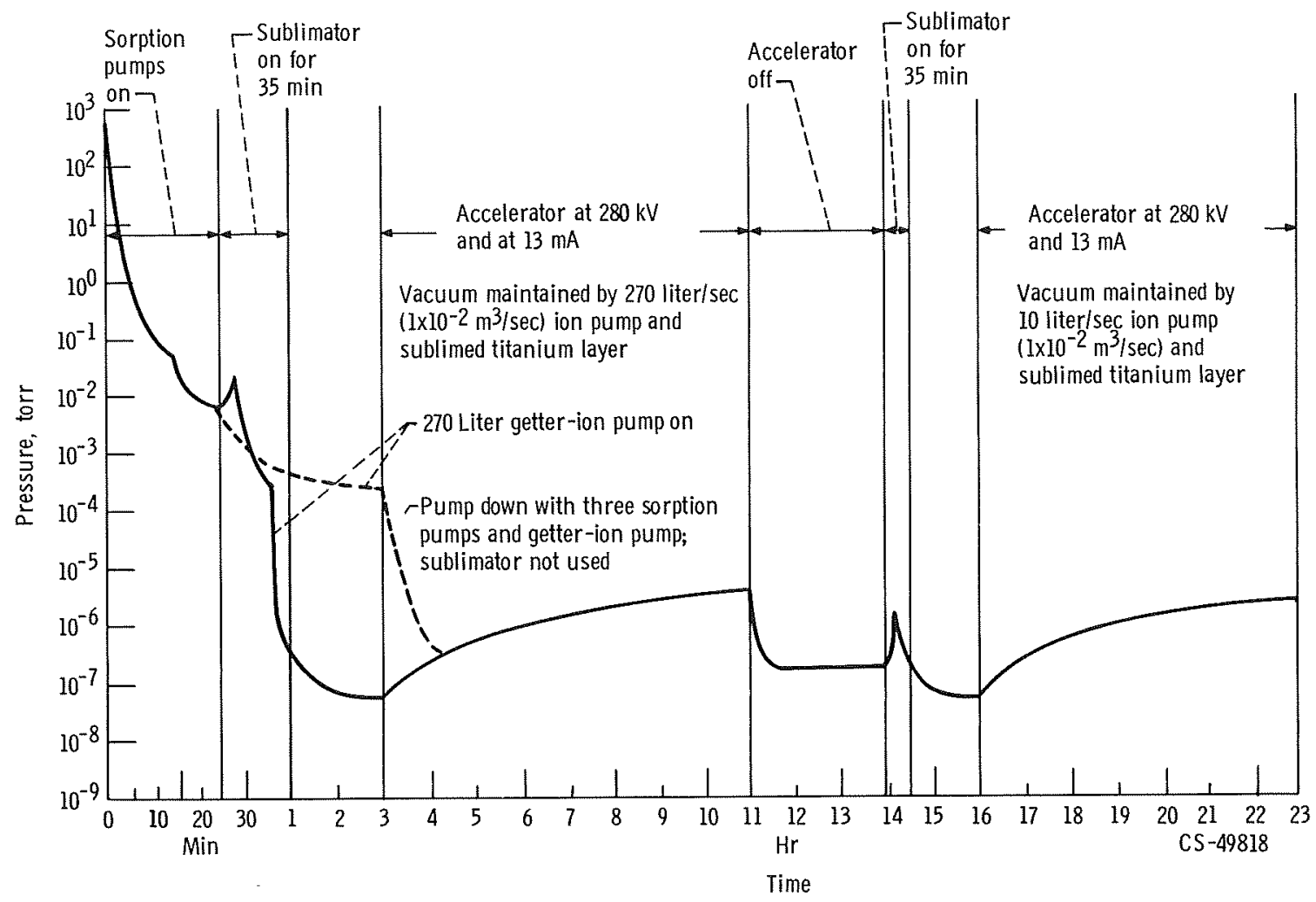

Figure 1. - Pumpdown and operating cycle for vacuum system of 300 kilovolt accelerator with and without use of bulk sublimator pump. 
routinely in this range, and there has never been a glow discharge or arcing problem. As shown by the solid line of figure 1 , the vacuum system now normally can be brought from atmosphere to $5 \times 10^{-7}$ torr in 1 hour with the aid of the TBS. The solid curve of figure 1 also shows that a layer of titanium deposited for 35 minutes will permit accelerator operation at 280 kilovolts and 13 milliamperes for at least 8 hours, during which time the operating pressure rises to an arbitrary cutoff limit of $5 \times 10^{-6}$ torr. During this operating period, the sublimator is "off" and only the getter ion pump is in operation. The previously sublimed titanium layer pumps the active gases while the getter-ion pump removes the residual hydrocarbons and inert gas load. The TBS can be operated continuously while simultaneously admitting gas to the system (continuous mode); or intermittently by first depositing a layer of titanium and then admitting gas (batch mode). Operating in the batch mode as shown in figure 1 has the advantage of more efficient utilization of titanium, while operating continuously can waste titanium. (An efficient sublimator operating mode is discussed in the next section.)

In order to qualitatively determine the residual leakage and surface outgassing on this system, with a 27 atmosphere cubic-centimeter-per-hour gas load, the gate valve on the 270 -1iter-per-second $\left(0.27-\mathrm{m}^{3} / \mathrm{sec}\right)$ ion pump was gradually closed. It was observed that the valve could be closed 33 out of a possible 34 turns without incurring any change in the system pressure! On an area basis this indicated that a 10-1iter-persecond $\left(1 \times 10^{-2}-\mathrm{m}^{3} / \mathrm{sec}\right)$ ion pump could hold the system. This conclusion was quantitatively verified by measuring the leakup rate of the system with all pumps and the deuterium source leak off. The sublimed titanium layer of course, was still pumping. It was calculated that a 4 -liter-per-second $\left(4 \times 10^{-3}-\mathrm{m}^{3} / \mathrm{sec}\right)$ pump could hold the system pressure. Since any ion pump might eventually become loaded with tritium, the use of a smaller capacity ion pump would make pump replacement significantly less expensive. Therefore, a 10-liter-per-second $\left(1 \times 10^{-2}-\mathrm{m}^{3} / \mathrm{sec}\right)$ ion pump was subsequently added to the system, and as expected it was capable of maintaining the vacuum during accelerator operation at full beam current. This is shown in figure 1 for the second operating cycle starting at 14 hours. The 10 -liter-per-second $\left(1 \times 10^{-2}-\mathrm{m}^{3} / \mathrm{sec}\right)$ pump was placed as an appendage on the sublimator chamber, as shown in figure 2. This location is particularly advantageous because the sublimed titanium surface strongly competes with the small getter-ion pump for deuterium gas and thus substantially reduces the effect of the high deuterium gas load on the ion pump cathodes and hence increases pump life.

If the 10-liter-per-second $\left(1 \times 10^{-2}-\mathrm{m}^{3} / \mathrm{sec}\right)$ pump could also provide sufficient capacity for startup from $1 \times 10^{-2}$ torr it could completely replace the 270 -liter-per-second $\left(0.27-\mathrm{m}^{3} / \mathrm{sec}\right)$ getter-ion pump. Figure 3 shows a system pumpdown attempt using only the 10 -liter-per-second $\left(1 \times 10^{-2}-\mathrm{m}^{3} / \mathrm{sec}\right)$ getter-ion pump and the effect of introducing the TBS. It can be seen that the 10 -liter-per-second $\left(1 \times 10^{-2}-\mathrm{m}^{3} / \mathrm{sec}\right)$ pump can indeed 

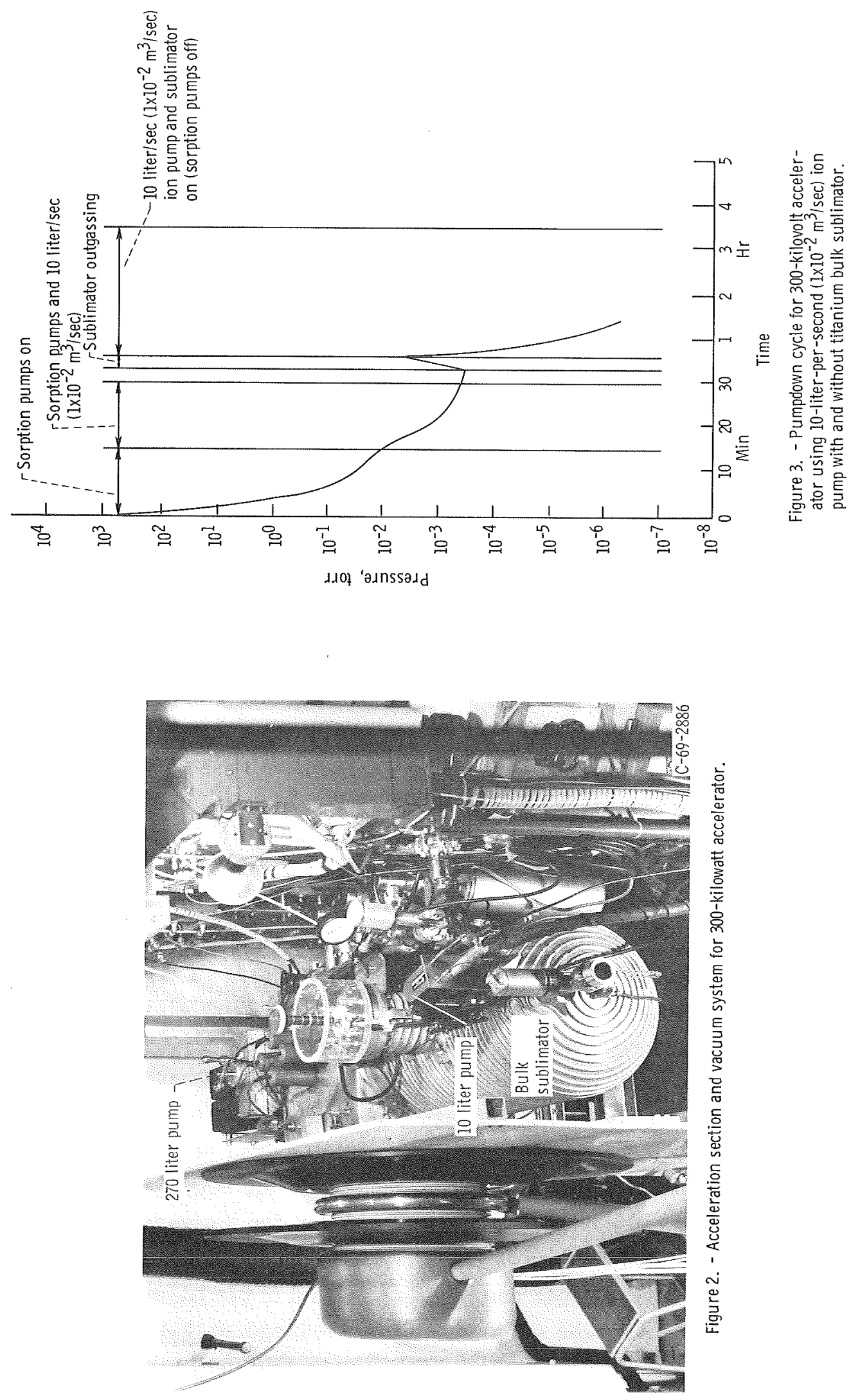
replace the 270 -liter-per-second $\left(0.27-\mathrm{m}^{3} / \mathrm{sec}\right)$ pump for pumping down from $1 \times 10^{-2}$ torr when operated in conjunction with the TBS. The 10 -liter-per-second $\left(1 \times 10^{-2}\right.$ $\mathrm{m}^{3} / \mathrm{sec}$ ) pump has water cooled cathodes and has a high throughput at high pressures compared to the 270 -liter-per-second $\left(0.27-\mathrm{m}^{3} / \mathrm{sec}\right)$ ion pump.

The vacuum system presently being used on the 300-kilovolt accelerator consisted of three sorption pumps, a TBS and a 10-liter-per-second $\left(1 \times 10^{-2}-\mathrm{m}^{3} / \mathrm{sec}\right)$ ion pump.

\section{SUBLIMATOR OPERATING MODE AND LIFETIME}

The TBS chamber used in the 300-kilovolt system is approximately 68.5 centimeters long by 45.6 centimeters in diameter and is water cooled. An area of 11600 square centimeters is available for sublimation. The pumping speed for deuterium is conductance limited by a water cooled baffle to 17600 liters per second $\left(17.6 \mathrm{~m}^{3} / \mathrm{sec}\right)$. The TBS uses a 400-gram rod of titanium; this is estimated to be sufficient for about $3 \frac{1}{2}$ years of operation assuming complete utilization of the 400 -gram rod by the formation of the full stoichiometric deuteride $\left(\mathrm{TiD}_{2}\right)$. The source consumes about 27 atmosphere cubic centimeters of deuterium per hour.

Whether the full stoichiometric deuteride is formed will depend in a large measure on the mode of operation of the TBS. If the sublimator is operated in a continuous mode, much of the deposited titanium will not be used. For example, assuming a titaniumtitanium spacing of $3 \AA\left(3^{-10} \mathrm{~m}\right)$, it would require $1.3 \times 10^{19}$ atoms of titanium to form a monolayer over the available sublimator substrate. At a sublimation rate of 1 gram per hour, $3.5 \times 10^{18}$ atoms of titanium are deposited each second onto the sublimed surface and in a little over 3 seconds a monolayer has been formed. With a deuterium gas leak rate of 27 atmosphere cubic centimeters per hour ( $4 \times 10^{17}$ atoms/sec), even if we assumed that $\mathrm{T}_{1}$ is formed, over eight times as much titanium as can be effectively used is being deposited onto the substrate each second.

Operation in the batch mode is certainly to be preferred if full utilization of the available titanium is desired. When tritium is pumped, the desire for a long maintainence free state may become an overriding consideration. Because substantial quantities of hydrogen can readily diffuse through titanium at room temperature, operation in the batch mode will allow most of the deposited titanium to be utilized if the vacuum necessary for accelerator operation is maintained while the deuterium gas is allowed to diffuse into the titanium substrate. This suggested that for a given deuterium gas leak the available substrate should be made large enough so that the majority of the titanium sites can be filled providing almost complete utilization of the titanium. We, in fact, have observed that by providing a surface sufficiently large so that, when the rates at which deuterium is leaked into the system and diffuses into the titanium substrate are 
approximately equal, the most efficient utilization of titanium occurs. Our initial results indicate that virtually all of the previously deposited titanium which has not formed deuterides, oxides, or nitrides is still accessible by diffusion, and that the titanium deuteride thus formed approaches the stoichiometric value $\mathrm{TiD}_{2}$.

While our present results are reproducible, it should be realized that other factors not fully specified herein may affect diffusion of deuterium in titanium and one must therefore be cautious in applying this method to other systems.

\section{PROPOSED VACUUM SYSTEM FOR 150-KILOVOLT ACCELERATOR}

A 150-kilovolt accelerator of the type widely used for research and for the production of neutrons can be readily adapted for a combination sublimation/ion pumping system. Normally one or two zeolite sorption pumps will rough the system down to $1 \times 10^{-2}$ torr quite rapidly. It is estimated that a suitable TBS and a small 10-liter-per-second $\left(1 \times 10^{-2}-\mathrm{m}^{3} / \mathrm{sec}\right)$ getter ion pump should be able to take the system down into the $10^{-7}$ torr range in about 30 minutes from the start of the pumpdown cycle.

For this application a separate sublimation chamber need not be required. The titanium can be sublimed directly into the vacuum manifold, utilizing an optical baffle to keep the titanium out of any undesirable areas. The baffle could also permit operation of the TBS while the accelerator was in operation. The vacuum manifold should be water cooled and be provided with a small viewing port so that the end of the titanium rod is visible. Viewing the rod occasionally is desirable to assure proper operation of the TBS.

As was previously pointed out, some caution must be exercised in applying the experience on the 300-kilovolt vacuum system to that for a 150-kilovolt machine. Nevertheless doing so provides some idea as to the size of the sublimator pumping system required for operation in the batch mode. Based on the 300-kilovolt system, a vacuum manifold 30 centimeters in diameter and 30 centimeters in length should provide an effective subliming surface for the 150-kilovolt accelerator, which requires a deuterium gas leak rate of 5 atmosphere cubic centimeters per hour. Although physically about the same size as a 140 -liter-per-second $\left(0.14-\mathrm{m}^{3} / \mathrm{sec}\right)$ ion pump that is normally used on a 150-kilovolt machine, the TBS (assuming no conductance limitation) should be capable of pumping deuterium at over 10000 liters per second $\left(10 \mathrm{~m}^{3} / \mathrm{sec}\right)$ in the operating pressure range.

Since the ion source for the 150-kilovolt machine requires about 5 atmosphere cubic centimeters per hour, a 400-gram titanium rod should be expected to last about $4 \times 10^{4}$ hours under a continuous deuterium gas load. This estimate is based on operating the TBS in the batch mode as shown in figure 1. 
The combination of a TBS, a getter ion pump, and a sorption roughing system provides a completely sealed system, which is desirable when large tritium inventories are involved.

\section{CONCLUSIONS}

A combination of a titanium bulk sublimator (TBS) and a getter ion pump has been applied to the vacuum system of a 300-kilovolt accelerator used for the production of neutrons and offers the following advantages:

1. Routine pumpdown from atmosphere to $10^{-7}$ torr can be accomplished in 1 hour.

2. Pumping speed can be varied from several liters per second to over 17000 liters per second $\left(17 \mathrm{~m}^{3} / \mathrm{sec}\right)$ depending upon pumping requirements for hydrogen, oxygen, nitrogen, carbon monoxide, and water.

3 . It is estimated that a 400 -gram loading in a TBS should last for $3 \frac{1}{2}$ years in a 300 -kilovolt machine and over 10 years in a 150 -kilovolt vacuum system.

4. The system is completely sealed and provides for controlled venting of tritium absorbed during rough pumping.

5. Tritium released from the target is permanently buried in the walls of the sublimator as titanium titride; thus the hazard associated with pump maintenance is reduced substantially.

Operation of the titanium sublimator in the region where the deuterium gas leak into the vacuum system matches the diffusion of deuterium into the titanium substrate can significantly extend the life of the TBS. Use of this design criteria should prove valuable when applied to high-current low voltage accelerators that use highly loaded tritium targets.

Lewis Research Center,

National Aeronautics and Space Administration, Cleveland, Ohio, April 28, 1970, 129-02.

\section{REFERENCES}

1. Turner, C. M.; Marinuzzi, J. G.; and Bennett, G. W.: Improvement of Hydrogen Pumping Characteristics of Penning Discharge Getter-Ion Pumps. IEEE Trans. on Nucl. Sci., vol. NS-14, no. 3, June 1967, pp. 831-835. 
2. Clausing, R. E.: A Large Scale Pumping Experiment Using Vapor Deposited Titanium Films. 1961 Transactions of the Eighth National Vacuum Symposium. Vol. 1. Luther E. Preuss, ed., Macmillan Co., 1962, p. 345.

3. Berger, James D.; Watson, Evelyn E.; and Cloutier, Roger J.: Health Physics Aspects of Low-Energy Accelerator. Proceedings of the Conference on the Use of Small Accelerators for Teaching and Research. Jerome L. Duggan, ed. AEC Rep. CONF-680411, 1968, pp. 112-137. 


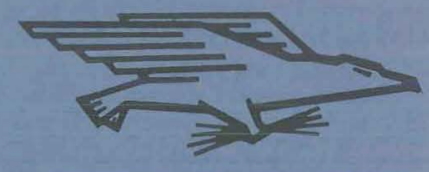

POSTAGE AND FEES PAID NATIONAL AERONAUTICS AND SPACE ADMINISTRATION

"The aeronantical and space activities of the United States shall be conducted so as to contribute... to the expansion of buman knowledge of phenomend in the atmosphere and space. The Administration shall provide for the widest practicable and appropriate dissemination of information concerning its activities and the results thereof."

\title{
NASA SCIENTIFIC AND TECHNICAL PUBLICATIONS
}

TECHNICAL REPORTS: Scientific and technical information considered important, complete, and a lasting contribution to existing knowledge.

TECHNICAL NOTES: Information less broad in scope but nevertheless of importance as a contribution to existing knowledge.

\section{TECHNICAL MEMORANDUMS:}

Information receiving limited distribution because of preliminary data, security classification, or other reasons.

CONTRACTOR REPORTS: Scientific and technical information generated under a NASA contract or grant and considered an important contribution to existing knowledge.
TECHNICAL TRANSLATIONS: Information published in a foreign language considered to merit NASA distribution in English.

SPECIAL PUBLICATIONS: Information derived from or of value to NASA activities. Publications include conference proceedings, monographs, data compilations, handbooks, sourcebooks, and special bibliographies.

\section{TECHNOLOGY UTILIZATION}

PUBLICATIONS: Information on technology used by NASA that may be of particular interest in commercial and other non-aerospace applications. Publications include Tech Briefs, Technology Utilization Reports and Notes, and Technology Surveys.

Details on the availability of these publications may be obtained from:

\author{
SCIENTIFIC AND TECHNICAL INFORMATION DIVISION
}

NATIONAL AERONAUTICS AND SPACE ADMINISTRATION

Washington, D.C. 20546 